\title{
Catalytic enantioselective synthesis of $\alpha$-chiral azaheteroaryl ethylamines by asymmetric protonation
}

\author{
Chao Xu, ${ }^{[a]}$ Calum W. Muir, ${ }^{[b]}$ Andrew G. Leach, ${ }^{[c]}$ Alan R. Kennedy, ${ }^{[b]}$ and Allan J. B. Watson ${ }^{[a] *}$
}

\begin{abstract}
The direct enantioselective synthesis of chiral azaheteroarylethylamines from vinyl aza-heterocycles and anilines is reported. A chiral phosphoric acid (CPA) catalyst promotes dearomatizing aza-Michael addition giving a prochiral exocyclic aryl enamine, which undergoes asymmetric protonation upon rearomatization. The reaction accommodates a broad range of azaheterocycle, nucleophile, and substituent on the prochiral centre, generating the products in high enantioselectivity. DFT studies support a facile nucleophilic addition based on catalyst-induced LUMO lowering, with site-selective, rate-limiting, intramolecular asymmetric proton transfer from the ion-paired prochiral intermediate.
\end{abstract}

(Hetero)arylethylamines are prolific in natural and synthetic bioactive molecules and pharmaceuticals for numerous disease indications. ${ }^{[1]} \quad$ Natural substances such as adrenaline, amphetamine, histamine, and thyroxine are critically important to human health and have been used as templates for the development of treatments for a broad range of disease states. Access to de novo chiral scaffolds has proven valuable for the development of new ligands for discrete targets (e.g., Scheme 1a).

On heterocyclic scaffolds, numerous approaches have been made to allow formation of the $\alpha$ - and $\beta$-stereocentre. ${ }^{[2,3]}$ However, methods to directly access the $\alpha$-stereocentre on the $\beta$-amino template are rare. Asymmetric hydrogenation is perhaps the most effective but requires prior synthesis of an enamine precursor, ${ }^{[4]}$ while hydroamination is generally more effective intramolecularly. ${ }^{[5]}$

Here, we present a method for the asymmetric synthesis of this important compound class based on a chiral phosphoric acid (CPA)-catalyzed dearomatizing aza-Michael/rearomatizing asymmetric protonation of 1,1-vinyl azaheterocycles (Scheme 1b). This provides direct modular access to chiral azaheteroarylethyl amines from simple precursors via the formation of a new $\mathrm{C}-\mathrm{N}$ bond, and with concomitant formation of the $\alpha$-stereocentre in high enantioselectivity. ${ }^{[6]}$ DFT studies are presented to rationalize the observed reactivity as well as the origin of the asymmetric induction.

[a] Dr C. Xu, Dr A. J. B. Watson EaStCHEM, School of Chemistry University of St Andrews

North Haugh, St Andrews, Fife, KY16 9ST (UK)

E-mail: aw260@st-andrews.ac.uk

[b] C. W. Muir, Dr A. R. Kennedy

Department of Pure and Applied Chemistry

University of Strathclyde

295 Cathedral Street, Glasgow, G1 1XL (UK)

[c] Dr A. G. Leach

School of Pharmacy and Biomolecular Sciences

Liverpool John Moores University

Byrom Street, Liverpool L3 3AF (UK)

Supporting information for this article is given via a link at the end of the document.

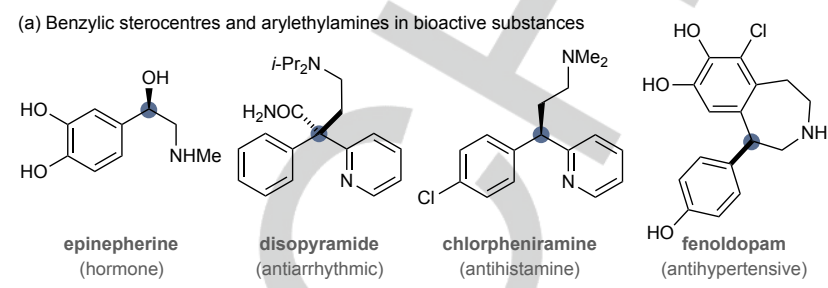

(b) Design plan. An asymmetric protonation approach

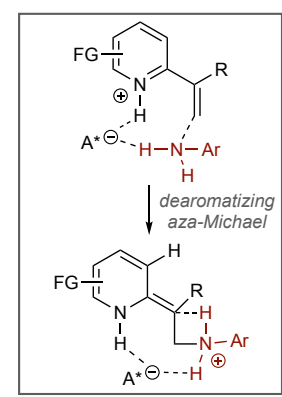

Scheme 1. (a) Examples of (hetero)arylethylamines. (b) This work: (Hetero)arylethylamines via conjugate addition/asymmetric protonation.

Vinyl heterocycles are competent conjugate acceptors ${ }^{[2]}$ and aza-Michael addition to vinyl heterocycles has been shown to proceed in refluxing $\mathrm{AcOH}^{[7]}$ We reasoned that a CPA catalyst might allow LUMO-lowering protonation of a 1,1-disubstituted 2vinyl azaheterocycle to allow a more facile reaction (Scheme 1b). ${ }^{[8,9]}$ Subsequent asymmetric protonation upon rearomatization would set the $\alpha$-stereocentre. ${ }^{[10-12]}$ While seemingly straightforward, the system must be $\mathrm{p} K_{a}$ balanced. Since both reactants and the product would contain Lewis basic sites, mismatched $\mathrm{p} K_{a}$ may inhibit catalyst turnover. Enantiofacial control during the key asymmetric protonation event would be catalyst-driven and contingent on high diastereocontrol in the formation of the prochiral enamine intermediate, enforced by $\mathrm{H}$-bonding between the catalyst and both reactants during the dearomatizing nucleophilic addition.

Using an amine nucleophile, the dearomatizing conjugate addition would likely be reversible. As such, we hypothesized that the dearomatization would be facilitated by the retention of a benzenoid ring. Accordingly, initial reaction development was based on the 1,1-disubstituted 2-vinyl quinoline 1 and aniline 2 as our benchmark system. An initial round of screening of CPAs identified the widely successful TRIP catalyst $\mathbf{3}$ as the most promising (Table 1, see ESI for full details of catalyst investigation). ${ }^{[10,11,13]}$ Stronger CPAs were ineffective, which we attribute to ineffective catalyst turnover due to the weaker conjugate base. No conversion was recorded in the absence of catalyst (entry 1); however, $73 \%$ conversion to 4 a with $91: 9$ e.r. was recorded using $20 \mathrm{~mol} \% 3$ at $0{ }^{\circ} \mathrm{C}$ (entry 2) with THF found to be the most suitable solvent (entries 2-6). Optimization of catalyst and nucleophile loading and temperature (entries 7-11) delivered an effective system that provided $75 \%$ conversion to 4a with $97: 3$ e.r. using $20 \mathrm{~mol} \% 3$ at $-20{ }^{\circ} \mathrm{C}$ (entry 9). Lower 
catalyst loadings were not favorable over same reaction time period (entries 10 and 11$)^{\dagger}$

Table 1. Reaction development. ${ }^{[a]}$

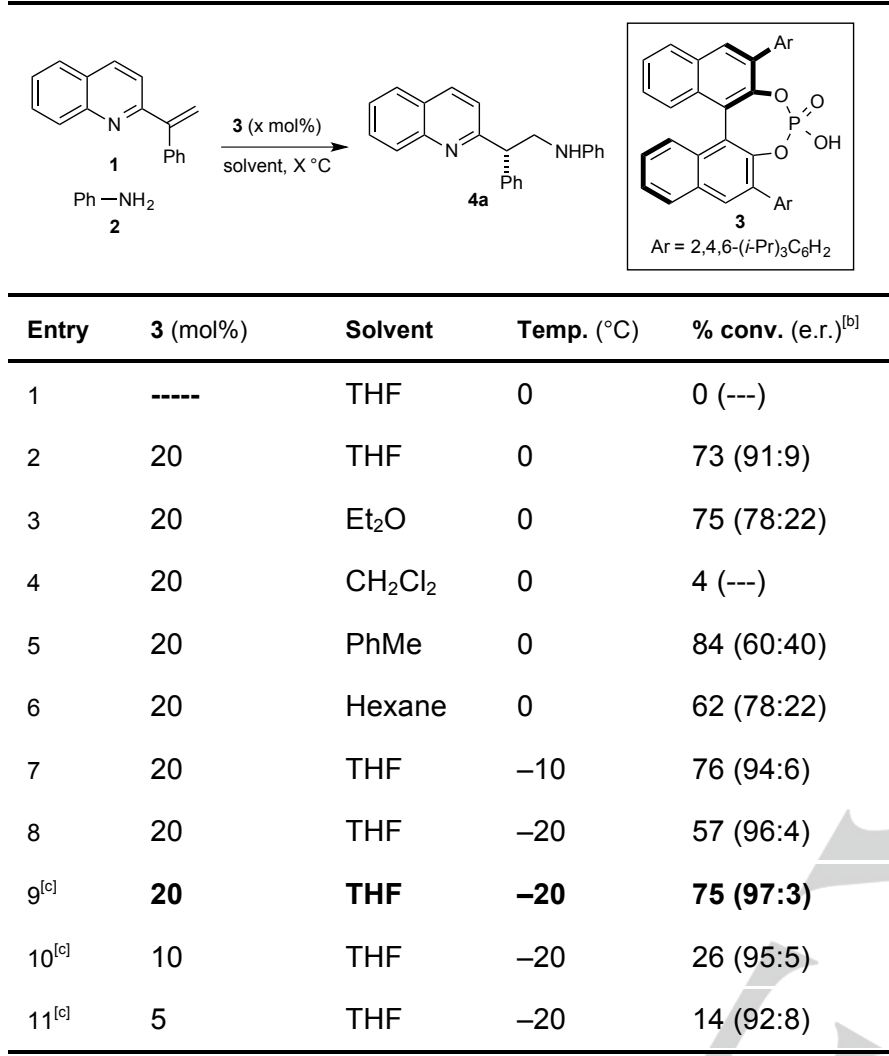

[a] 1 (1 equiv), 2 (2 equiv), solvent (0.5 M). [b] Determined by HPLC analysis. See ESI. [c] Using 3 equiv 2.

The generality of the method is shown in Scheme 2. A broad range of aniline was tolerated, with small variations of efficiency and selectivity as a function of the electronic parameters of the anilines, in line with DFT observations of key $\pi$-stacking interactions (vide infra). Alkyl amines were not successful due to catalyst inhibition through salt formation (not shown, see ESI). The substituent on the prochiral center could be varied to a range of aryl units without major impact on the enantioselectivity (Scheme 2b). Alkyl groups were not tolerated well, giving moderate enantioselectivity (not shown; see ESI), which we believe stems from the removal of key $\pi$-stacking interactions between the components (vide infra).
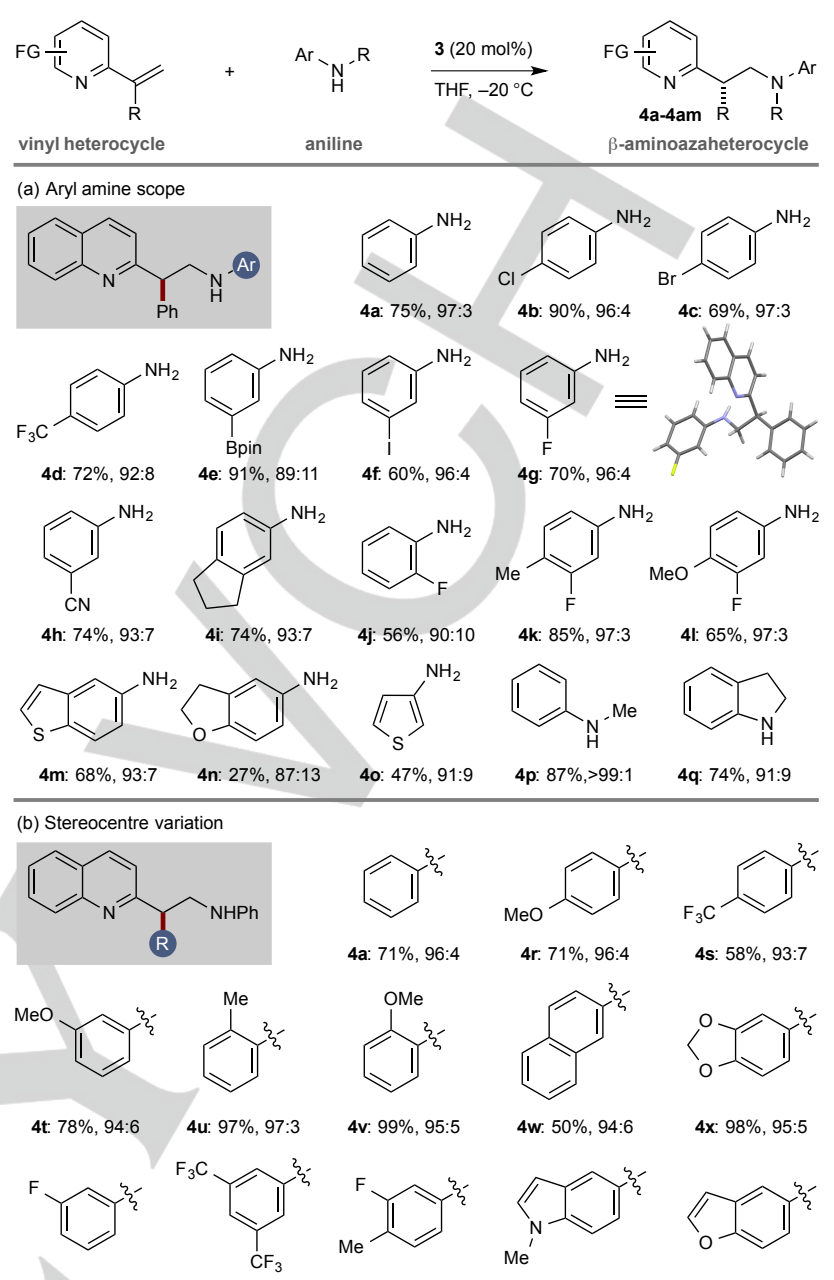

$\begin{array}{lllll}\text { 4y: } 77 \%, 95: 5 & \text { 4z: } 86 \%, 97: 3 & \text { 4aa: } 99 \%, 96: 4 & \text { 4ab: } 53 \%, 95: 5 & \text { 4ac: } 69 \%, 95: 5\end{array}$
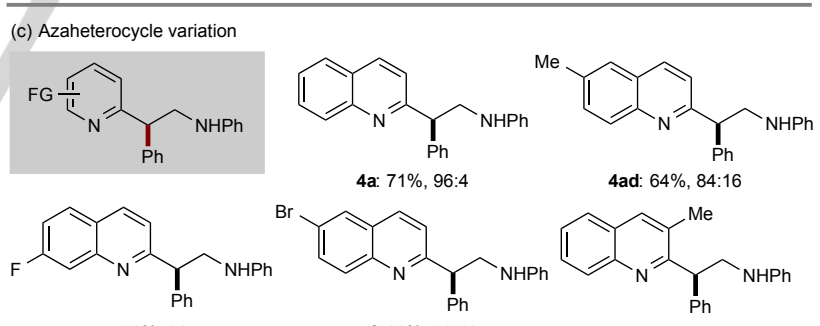

4ae: $96 \%, 96: 4$

4af. $66 \%, 90: 10$

4ag: $31 \%, 51: 49^{a}$
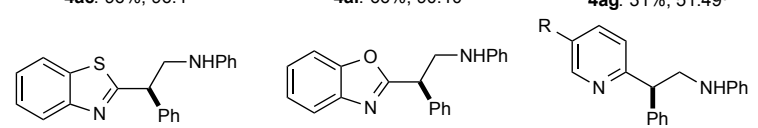

4ah: $94 \%, 92: 8$

4ai: $56 \%, 69: 31$

$\mathrm{R}=\mathrm{H}, 4 \mathrm{aj}: 37 \%, 57: 43^{\mathrm{a}}$

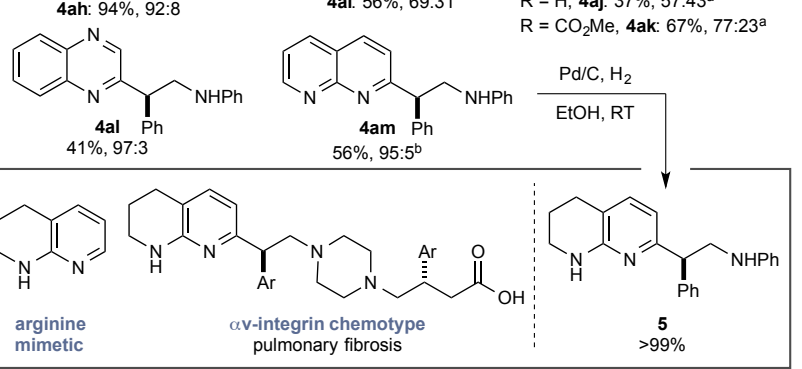

Scheme 2. Substrate scope. Isolated yields. Enantiomeric ratio determined by HPLC analysis. See ESI. ${ }^{a}$ Reaction temp. $=40{ }^{\circ} \mathrm{C}$. ${ }^{b}$ Using $100 \mathrm{~mol} \% 3$ at -40 ${ }^{\circ} \mathrm{C}$ 
Lastly, the azaheterocycle could be varied to a number of derivatives, adhering to the regiochemical requirements of the vinyl unit (Scheme 2c). Less reactive heterocyclic templates required increased temperature for reactivity (4aj, 4ak), which compromised enantioinduction. Introducing a substituent to the 3-positon of the quinoline (4ag) template led to major negative effects on conversion and selectivity, due to allylic strain consistent with the mechanistic rationale (vide infra), while some stark selectivity variance was observed between similar heterocyclic templates based on electronic differences (e.g., 4ah, 4ai).

An example of potential utility in medicinal chemistry is shown from 4am. Hydrogenation of naphthyridine $4 \mathrm{am}$ delivers piperidinopyridine scaffold $\mathbf{5}$, an arginine mimetic ${ }^{[14]}$ and, specifically, a key pharmacophore within RGD $\alpha$ v-integrin drug discovery. ${ }^{[15]}$

The mechanism of the process was rationalized by DFT calculations (Scheme 3). ${ }^{[16]}$ Protonation of the substrate 1 by catalyst 6 leads to LUMO-lowered pyridinium ion pair 7, which also benefits from a $\mathrm{CH}-\mathrm{O}$ hydrogen bond between the $\mathrm{C} 8 \mathrm{H}$ and another of the phosphate oxygens $(\mathrm{H}-\mathrm{O}=2.33 \AA)$. $\mathrm{H}$ bonding interactions between the catalyst, heterocycle, and incoming nucleophile (2) orients 2 to pick up additional $\pi$ stacking interactions with the aryl substituent on the prochiral centre (phenyl, in the model shown), enforcing high levels of diastereocontrol in the formation of the prochiral enamine in the subsequent conjugate addition. Based on this preorganization, the addition is a surprisingly low energy process proceeding via TS1 to deliver the key prochiral E-enamine intermediate ion pair 8. This intermediate cannot be observed (NMR) based on the

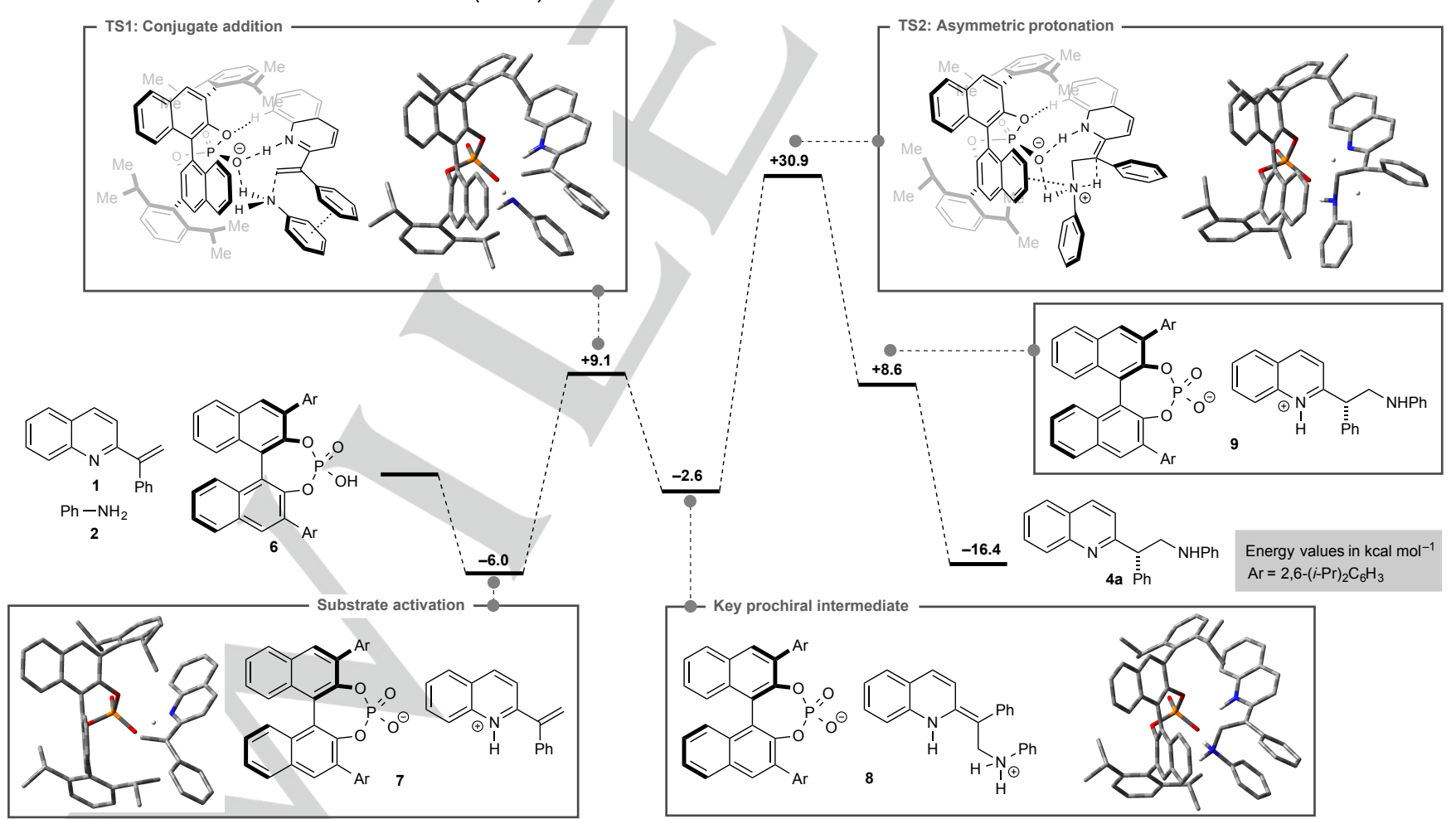

pre-RLS equilibrium. The $\mathrm{C}-\mathrm{N}$ bond in this intermediate is weak $(\mathrm{C}-\mathrm{N}=1.57 \AA)$ and the species relies on stabilization via a strong hydrogen bond between the anilinium ion and the phosphate oxygen $(\mathrm{N}-\mathrm{H} \ldots \mathrm{O}=\mathrm{P}, \mathrm{N}-\mathrm{H}=1.12 \AA$ and $\mathrm{H}-\mathrm{O}=1.42 \AA)$. The anilinium also benefits from a $\pi$-cation interaction with the catalyst. The retention of the quinolinium-phosphate $\mathrm{H}$-bond, the anilinium-phosphate $\mathrm{H}$-bond, and the $\mathrm{CH}-\mathrm{O} \mathrm{H}$-bond imposes tight geometric limits on the bound substrate. Alternative modes of aniline addition are significantly disfavored (not shown, see ESI for details).

Ion pair 8 undergoes the rate-limiting rearomatizing asymmetric protonation. Using the $R$-catalyst (shown), this gives preferential protonation of the $R e$-face of the enamine to deliver the S-product, proceeding via 4- membered transition state TS2, transferring the proton from the anilinic ammonium rather than heterocyclic $\mathrm{NH}$ to deliver the quinolinium product ion pair $\mathbf{9}$. This event is favored by ca. $0.7 \mathrm{kcal} \mathrm{mol}^{-1}$ over the alternative protonation of the Si-face. Interestingly, $\mathrm{H}$-bonding of the chiral anion to the heterocyclic $\mathrm{NH}$ and an anilinium $\mathrm{NH}$ controls this protonation event, but the anion is not involved as a proton shuttle. The three anchoring polar interactions are retained in the transition state. A key observation from these calculations was the product ion pair complex $\mathbf{9}$ is higher in free energy than substrate activation complex 7 , which suggests no product inhibition of the catalysis. An intramolecular $\mathrm{H}$-bonding interaction between the newly installed aniline $\mathrm{NH}$ and the heterocyclic nitrogen, as observed in solid state (e.g., $\mathbf{4 g}$, Scheme $2 \mathrm{a}$ ), may explain tempered Lewis basicity in the product, facilitating catalyst turnover.

Scheme 3. DFT calculated energy profile for preferred pathway. Free energies in $\mathrm{kcal} / \mathrm{mol}$ (computed at $298 \mathrm{~K}$ with corrections to 1 M) were computed at the M06-2X/6-31+G* $\left(+\right.$ IEFPCM)//M06-2X/3-21G level of theory. ${ }^{[17-21]}$ 
Preliminary kinetic studies support a $1^{\text {st }}$ order dependency with respect to all three components (vinyl heterocycle, aniline nucleophile, and catalyst), consistent with the DFT analysis (see ESI). Finally, ${ }^{31} \mathrm{P}$ NMR and HRMS analysis supported a preferential substrate/catalyst pairing (i.e., 1.3) rather than product/catalyst (i.e., $\mathbf{4 a \cdot 3}$ ), consistent with the turnover hypothesis (see ESI).

In summary, we have developed a CPA-catalyzed enantioselective synthesis of $\alpha$-chiral azaheteroaryl ethylamines via dearomatizing aza-Michael/rearomatizing asymmetric protonation. DFT and kinetic studies have given insight into the mechanism of the reaction, which will guide future applications of this approach towards the design and synthesis of functionalized heterocyclic scaffolds.

\section{Acknowledgements}

We thank the Leverhulme Trust for funding (C.X.; RPG-2015308) and GSK for a PhD studentship (C.W.M.). We thank the EPSRC UK National Mass Spectrometry Facility at Swansea University for analyses.

Keywords: asymmetric catalysis • Brønsted acid • DFT • heterocycles $\bullet$ stereochemistry

$\dagger \quad$ For preliminary assessment of non-linearity and $\mathrm{H}_{2} \mathrm{O}$ effects, see ESI

[1] For general information, see: (a) National Center for Biotechnology Information. PubChem Compound Database; CID=1001 https://pubchem.ncbi.nlm.nih.gov/compound/1001 (accessed Apr. 12, 2018); (b) The Merck Index - An Encyclopedia of Chemicals, Drugs, and Biologicals. $13^{\text {th }}$ Edition (Ed.M. J. O'Neil), Merck and Co., Inc., New Jersey, 2001.

[2] For a review on the general use of azaarenes in asymmetric catalysis, see: D. Best, H. W. Lam, J. Org. Chem. 2014, 79, 831-845.

[3] For selected examples, see: (a) Q. Hu, A. Kondoh, M. Terada, Chem. Sci. 2018, 9, 4348-4351; (b) G. Bertuzzi, D. Pecorari, L. Bernardi, M Fochi, Chem. Commun. 2018, 54, 3977-3980; (c) S. Yu, H. L. Sang, S. Ge, Angew. Chem. Int. Ed. 2017, 56, 15896-15900; Angew. Chem. 2017, 129, 16112-16116; (d) M. Meazza, F. Tur, N. Hammer, K. A Jørgensen, Angew. Chem. Int. Ed. 2017, 56, 1634-1638; Angew. Chem. 2017, 129, 1656-1660; (e) J. Izquierdo, A. Landa, I. Bastida, R. López, M. Oiarbide, C. Palomo, J. Am. Chem. Soc. 2016, 138, 3282 3285; (f) Y.-Y. Wang, K. Kanomata, T. Korenaga, M. Terada, Angew. Chem. Int. Ed. 2016, 55, 927-931; Angew. Chem. 2016, 128, 939-943; (g) H. B. Hepburn, P. Melchiorre, Chem. Commun. 2016, 52, 35203523; (h) A. Saxena, B. Choi, H. W. Lam, J. Am. Chem. Soc. 2012, 134 8428-8431; (i) H.-W. Sun, Y.-H. Liao, Z.-J. Wu, H.-Y. Wang, X.-M Zhang, W.-C. Yuan, Tetrahedron 2011, 67, 3991-3996; (j) G. Pattison, G. Piraux, H. W. Lam, J. Am. Chem. Soc. 2010, 132, 14373-14375; (k) L. Rupnicki, A. Saxena, H. W. Lam, J. Am. Chem. Soc. 2009, 131, 10386-10387; (I) A. Baschieri, L. Bernardi, A. Ricci, S. Suresh, M. F. A Adamo, Angew. Chem. Int. Ed. 2009, 48, 9342-9345; Angew. Chem. 2009, 121, 9506-9509.
[4] For a review of asymmetric hydrogenation of enamines, see: J.-H. Xie, S.-F. Zhu, Q.-L. Zhou, Chem. Rev. 2011, 111, 1713-1760.

[5] T. E. Müller, K. C. Hultzsch, M. Yus, H. Foubelo, M. Tada, Chem. Rev. 2008, 108, 3795-3892.

[6] During the preparation of this manuscript, two reports of catalytic enantioselective preparation of $\alpha$-stereocentres using a combined CPA/photoredox catalysis approach were reported. See: (a) R. S. J. Proctor, H. J. Davis, R. J. Phipps, Science DOI:10.1126/science.aar6376; (b) Y. Yin, Y. Dai, H. Jia, J. Li, L. Bu, B. Qiao, X. Zhao, Z. Jiang, J. Am. Chem. Soc. 2018, 140, 6083-6087.

[7] For examples, see: (a) H. E. Reich, R. Levine, J. Am. Chem. Soc. 1955, 77, 5434-5436; (b) H. E. Reich, R. Levine, R. J. Am. Chem. Soc. 1955, $77,4913-4915$

[8] For a recent CPA-catalyzed conjugate addition of a nucleophilic carbon radical to vinyl azaheterocycles, see ref $6 \mathrm{~b}$.

[9] For previous organocatalyzed conjugate addition to vinyl heterocycles, see refs $3 b$ and $3 e$.

[10] For reviews of chiral counterions in catalysis, see: (a) T. Akiyama, K. Mori, Chem. Rev. 2015, 115, 9277-9306; (b) M. Mahlau, B. List, Angew. Chem. Int. Ed. 2013, 52, 518-533; Angew. Chem. 2013, 125, 540-556; (c) K. Brak, E. N. Jacobsen, Angew. Chem. Int. Ed. 2013, 52, 534-561; Angew. Chem. 2013, 125, 558-588; (d) D. Kampen, C. M. Reisinger, B. List, Top. Curr. Chem. 2010, 291, 395-456; (e) T. Akiyama, Chem. Rev. 2007, 107, 5744-5758.

[11] For reviews of asymmetric protonation, see: (a) J. T. Mohr, A. Y. Hong, B. M. Stoltz, Nat. Chem. 2009, 1, 359-369; (b) S. Oudeyer, J.-F. Brière, V. Levacher, Eur. J. Org. Chem. 2014, 6103-6119; (c) J. P. Phelan, J. A. Ellman, Beilstein J. Org. Chem. 2016, 12, 1203-1228.

[12] For a recent demonstration of CPA-catalyzed enantioselective functionalization of olefins, see: N. Tsuji, J. L. Kennemur, T. Buyck, S. Lee, S. Prévost, P. S. J. Kaib, D. Bykov, C. Farès, B. List, Science 2018, 359, 1501-1505.

[13] For a review, see: J. T. M. Correia, Synlett 2015, 26, 416-417.

[14] L. P. Masic, Curr. Med. Chem. 2006, 13, 3627-3648.

[15] For examples, see: R. J. D. Hatley, S. J. F. Macdonald, R. J. Slack, J. Le, S. B. Ludbrook, P. T. Lukey, Angew. Chem. Int. Ed. 2018, 57, 3298-3321; Angew. Chem. 2018, 130, 3354-3379.

[16] C. A. Hunter, Angew. Chem. Int. Ed. 2004, 43, 5310-5324; Angew. Chem. 2004, 116, 5424-5439.

[17] M. J. Frisch, G. W. Trucks, H. B. Schlegel, G. E. Scuseria, M. A. Robb, J. R. Cheeseman, G. Scalmani, V. Barone, G. A. Petersson, H. Nakatsuji, X. Li, M. Caricato, A. Marenich, J. Bloino, B. G. Janesko, R. Gomperts, B. Mennucci, H. P. Hratchian, J. V. Ortiz, A. F. Izmaylov, J. L. Sonnenberg, D. Williams-Young, F. Ding, F. Lipparini, F. Egidi, J. Goings, B. Peng, A. Petrone, T. Henderson, D. Ranasinghe, V. G. Zakrzewski, J. Gao, N. Rega, G. Zheng, W. Liang, M. Hada, M. Ehara, K. Toyota, R. Fukuda, J. Hasegawa, M. Ishida, T. Nakajima, Y. Honda, O. Kitao, H. Nakai, T. Vreven, K. Throssell, J. A. Montgomery, Jr., J. E. Peralta, F. Ogliaro, M. Bearpark, J. J. Heyd, E. Brothers, K. N. Kudin, V. N. Staroverov, T. Keith, R. Kobayashi, J. Normand, K. Raghavachari, A. Rendell, J. C. Burant, S. S. Iyengar, J. Tomasi, M. Cossi, J. M. Millam, M. Klene, C. Adamo, R. Cammi, J. W. Ochterski, R. L. Martin, K. Morokuma, O. Farkas, J. B. Foresman, D. J. Fox, Gaussian, Inc.: Wallingford CT, 2009.

[18] Y. Zhao, D. G. Truhlar, Acc. Chem. Res. 2008, 41, 157-167.

[19] Y. Zhao, D. G. Truhlar, Theor. Chem. Acc. 2008, 120, 215-241.

[20] J. Tomasi, B. Mennucci, R. Cammi, Chem. Rev. 2005, 105, 2999-3094.

[21] P. C. Hariharan, J. A. Pople, Theor. Chim. Acta 1973, 28, 213-222. 


\section{Entry for the Table of Contents}

\section{COMMUNICATION}

$$
\text { vinyl heterocycle aniline }
$$

(S)-TRIP tease. The direct enantioselective synthesis of chiral

azaheteroarylethylamines from vinyl aza-heterocycles and anilines is reported. A chiral phosphoric acid (CPA) catalyst promotes dearomatizing aza-Michael addition to generate a prochiral exocyclic aryl enamine, which undergoes asymmetric protonation upon rearomatization giving the products in high selectivity. DFT studies have provided insight into the mechanism.
Chao Xu, Calum W. Muir, Andrew G. Leach, Alan R. Kennedy, and Allan J. B. Watson*

Page No. - Page No.

Catalytic enantioselective synthesis of $\alpha$-chiral azaheteroaryl ethylamines by asymmetric protonation 